\title{
Consumption, Solid Waste Generation and Water Pollution in Pinga Oya Catchment area
}

\author{
M.T.M. Mahees, C. Sivayoganathan ${ }^{{ }^{*}}$ and B.F.A. Basnayake ${ }^{2}$ \\ Postgraduate Institute of Agriculture \\ University of Peradeniya \\ Sri Lanka
}

\begin{abstract}
This study focuses on the effects of socioeconomic and political factors in solid waste generation and water pollution in the catchments of Pinga Oya, a tributary of the Mahaweli river. The direct solid waste disposal into water bodies and the untreated dumping sites are supposed to be some of the major causes of water pollution in Sri Lanka. The main objectives of this paper were to determine and evaluate the causal link between consumption pattern and solid waste generation and to understand the underlining socio-economic stories of waste disposal and their link with water pollution. Semi-structured household questionnaires (200) and in-depth interviews with key informants were used to collect quantitative and qualitative data from Pinga Oya watershed areas. The samples were selected on stratified basis and purposively and data were analysed quantitatively and qualitatively. The secondary information was mostly collected from the sociological literature. The consumption patterns of people often determine the nature and amount of solid waste generation based on their livelihood, class and culture. Here, the symbolic consumption which has become the life style of urban middle and upper class people, promotes a "consumer society" with the influence of monthly household income and cultural ritual. As a result of higher social value given for mass consumption in this global economic order, people frequently consume unwanted goods to achieve symbolic value and cultural satisfaction rather than limiting their consumption to actual necessities. This study revealed that there was a positive relationship between the monthly household income and consumption pattern and people with the higher monthly household income (>Rs.25,000) generate more solid waste daily (1.5-2 kg) than low income groups. The domestic solid waste generation was mainly influenced by weekly food consumption $\left(R^{2}=0.61\right)$. The family size and gender relationship of consumer behaviour were also found significant in determining solid waste generation. This consumption culture that generates more and more solid waste especially in urban social environment influences the quality of water and aggravates the crisis of water pollution. Therefore, water pollution created by solid waste disposal is not only a problem limited to natural scientists to solve but also a social problem caused by many socio-economic and cultural practices of people.
\end{abstract}

Key words: Consumerism, Waste generation, Water pollution.

To whom correspondence should be addressed: csivayoga@pdn.ac.lk Department of Agricultural Extension, University of Peradeniya, Sri Lanka

Department of Agricultural Engineering, University of Peradeniya, Sri Lanka 


\section{INTRODUCTION}

This paper basically attempts to examine the causal relationship between the consumption pattern and solid waste generation and its link with water pollution in river Mahaweli. The main objective of this paper is to understand the significance of consumption pattern in generating solid waste quantitatively and qualitatively and its impact on water pollution of Pinga Oya based on sociological literature and primary data. Although there are many studies done on the relationship between solid waste and water pollution at global level, the link between consumption pattern and solid waste generation has not been considered in any social science reviews or studies in Sri Lanka. Although the natural sciences have been dealing very much with the crisis of solid waste and water pollution, the relevant sociological perspectives are helpful to understand the actual subjective factors and forces of solid waste disposal and its connection with water pollution. Therefore, sociological or environmental sociological approach can realize subjective causes and effects of the solid waste disposal and water pollution in relation to other academic disciplines.

Solid waste generation is an inevitable consequence of production and consumption activities. Population growth can increase the amount of municipal solid waste significantly. However, the generation can also vary with the level of income, urbanization trend, changing food habit, social and cultural habits, and lifestyle changes. Seasonal variations also can influence the amount of waste generation. During the rainy season, the waste becomes wet and heavy. Plenty of vegetables and seasonal fruits are grown and lead to an incremental variation in waste amount.

Water of river Mahaweli is polluted mainly by soil erosion, chemical and agricultural pollutants, industrial pollution and solid waste disposal (The Ministry of Forestry and Environment, 2000). The solid waste disposal is one of the leading causes of water pollution in Pinga Oya due to many limitations encountered by local authorities. Most of the solid waste is dumped or processed as open dumping site on the river basins. According to Werellagama (2000), the degree of water pollution near the Polgolla reservoir (along the Pinga Oya) is as presented in Table 1 .

Table 1. The average water quality data of Mahaweli River near the Polgolla reservoir

\begin{tabular}{lc}
\hline Parameters and units of measurement & Value \\
\hline Temperature $\left({ }^{\circ} \mathrm{C}\right)$ & 26.1 \\
pH & 7.1 \\
DO $(\mathrm{mg} / \mathrm{L})$ & 3.2 \\
Turbidity $(\mathrm{NTU})$ & 34.6 \\
Suspended Solids $(\mathrm{mg} / \mathrm{L})$ & 53.0 \\
$\mathrm{BOD}_{5}(\mathrm{mg} / \mathrm{L})$ & 1.2 \\
$\mathrm{COD}(\mathrm{mg} / \mathrm{L})$ & 43.9 \\
$\mathrm{~N}-\mathrm{NO}_{3}(\mathrm{mg} / \mathrm{L})$ & 1.0 \\
$\mathrm{PO}_{4}{ }^{3-}(\mathrm{mg} / \mathrm{L})$ & 0.1 \\
Faecal Coliforms $/(100 \mathrm{ml})$ & 2790 \\
\hline
\end{tabular}

$D O$ - Dissolved oxygen; $\mathrm{BOD}_{5}$ - Biological oxygen demand on the day 5; COD-Chemical oxygen demand. 
Pinga Oya is one of the important tributaries of the Sri Lanka's longest river Mahaweli. The stream originates in the mild rolling terrain of Pujapitiya division of Kandy district in the Central Province and flows through a course of $6 \mathrm{~km}$ before it meets Mahaweli River just upstream of the Polgolla diversion barrage of the Mahaweli multipurpose irrigation scheme (Hettiarachchi, 2003). The upper part of the Pinga Oya catchment belongs to the Pujapitiya division which is a mildly populated rural and sub-urban area with a largely agricultural land use, whereas the down stream part belongs to the densely populated Akurana division. The stream runs through Akurana town which has the second highest population density in Sri Lanka (Census \& Statistics Department, 2007).

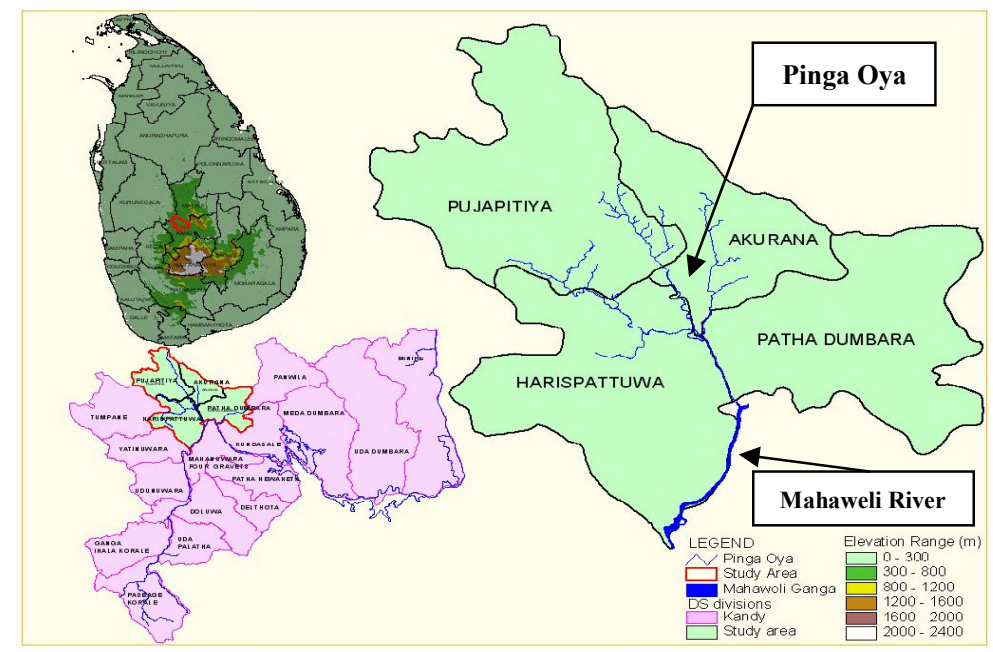

Fig. 1. The map of Pinga Oya catchment with four Divisional Secretariats

The socio-environmental problems suffered by the people and the ecosystem of Pinga Oya are principally caused by the densely populated downstream area. There are astoundingly immense numbers of large multi-storied buildings built illegally in the stream reservation and some of these buildings virtually stand on the stream bed. Since these encroachments were given political support and the attitude of the communities towards Pinga Oya was increasingly deteriorating in the face of profit motivated ideology promoted by changing socio-economic conditions, the degradation and destruction of this once reserved source life has gone unnoticed (Hettiarachchi, 2003).

In 2002, five tons of solid wastes were generated daily in the settlements along the banks of Pinga Oya, some of this waste was directly thrown into the stream while rest being dumped into the municipal open dump yard situated on a mountain top in the extreme upstream of Pinga Oya. Natural vegetation along the banks is being cleared in an increasing rate either for unauthorized development or for daily needs like firewood. Combined effect of all these activities has given rise to the following problems (Hettiarachchi, 2003).

In Pinga Oya, the average DO decreased from $5 \mathrm{mg} / \mathrm{l}$ to $4 \mathrm{mg} / \mathrm{l}$ and $\mathrm{NO}_{3}{ }^{-}-\mathrm{N}$ increased from $0.5 \mathrm{mg} / \mathrm{l}$ to $1.75 \mathrm{mg} / \mathrm{l} \mathrm{in} 2003$. Further, fecal colifrm levels as high as $7500 \mathrm{cfu} / 100 \mathrm{ml}$ were measured. There is a strong relationship between fecal pollution and human settlements indicating frequent biological contamination from human excreta and solid waste discharged from houses and shops (Herath, 2003). 
As consumption is a significant domain of day today life, it should not consider only selecting, purchasing and using of goods and services but should be defined broadly. The socio-cultural significance of consumption should also be recognized. The idea is that consumption is essentially a symbolic activity which creates order in the psychological world of individuals. Their idea has been widely accepted and applied. In contemporary society, consumers are active in attaching symbolic meanings to goods and services. Actually they are eagerly seeking the meanings and significance of goods. Contemporary, modern and postmodern, consumer theories admit that consumption is a social activity by which symbolic meanings as well as social codes and relations are produced and reproduced. In these theoretical perspectives consumption is viewed as full of hidden meanings, as creative work where day today life and cultural patterns are actively produced and reproduced (Uusitalo, 1996).

According to Jean Badrillard, who brought critical arguments of consumption through postmodern sociological perspective, since consumption activities are seen as surpassing reality, what is consumed are signs and symbols rather than material goods. Real goods are replaced by simulations, and a new reality is created which has lost its reference to the original. In effect, nothing else but symbols is consumed. Accordingly, consumption becomes a play by which symbols are created and manipulated. This is, according to Baudrillard, the world of hyperreality (Baudrillard, 1988).

Baudrillard is centrally considered with the idea of modern society as 'consumer society' in which extreme form of dehumanization has occurred and the objectives have taken over. The response of people is to make them as much like these objects as possible. Baudrillard sees society as being dominated by objects and pervaded by signs. Baudrillard sees the consumer society, with its apparently prosperous, comfortable and enriched lives of many, as a snare and a delusion, as a continuation of the traditionally exploitative nature of capitalism (Cuff, 2004).

According to Slater (1997), consumer culture is the culture of market societies and is defined through market relations. It predominantly is the product of capitalism. He believes that this new culture is a pecuniary culture based on money. The central claim is that the values from the realm of consumption will spill over into other domains of social action. He further argues that consumer culture is in principle, universal and impersonal. He simultaneously argues that there is an ulterior claim towards this definition, as although it seems universal and is depicted as a land of freedom, in which everyone can be a consumer, it is also felt to be universal because everybody must be a consumer. Another characteristic is that consumer culture is identified with private choice and private life. The next characteristic feature is that the consumer's needs are unlimited and insatiable. His last characteristic to the definition of consumer culture is that consumer culture represents the increasing importance of culture in the exercise of power.

It is obvious that people are not consuming but they are made to consume by various socioeconomic forces. Also, people do not consume goods and service but they consume symbols which are very much harmful to the environment and water resources.

According to the perspectives of sociology of consumption, there are four major factors influencing the situation and nature of consumer society of Sri Lanka. The higher level of household income is one of the leading factors influencing the consumption pattern. This situation is very common among the upper class or upper middle class people who usually purchase their goods from super-markets. On the other hand, many of the middle class 
people are concerned about the symbolic value of goods that they purchase and they mostly are engaged in the symbolic consumption. The third force that influences consumption is urban culture or subculture. This consumption pattern is quite popular among the low income groups and slum-dwellers in the cities. The last and the most significant force is electronic media which has totally changed the consumption pattern of almost every social class of Sri Lanka society. The mass culture has become a serious threat to the civil society of Sri Lanka by reproducing a new consumer culture.

\section{METHODOLOGY}

The questionnaire method is found very useful in understanding the field situation and collecting basic quantitative and qualitative information. For this purpose, 200 questionnaires were administrated on households located in Pinga Oya catchments, in the four Divisional Secretaries Akurana, Pujapitiya, Harispattuwa and Pathadumbara. The majority of questionnaires were administered in Akurana DS based on the physical proximity to the Pinga Oya. The number of questionnaires to be administered in each GN division depends on the size of the population. The sample of study was selected from the Grama Niladari Divisions of these four DS divisions which are physically closer to the Pinga Oya and its tributary canals. But, since this study mainly focuses on solid waste generation and water pollution, the GN Divisions of Akurana DS were given priority in selecting the sample.

The sample was selected purposively based on stratified social and physical categories. The main aim of using purposive sample is to include different respondents who represent various socio-economic, cultural, and educational and gender backgrounds.

The in-depth interview method was the major data collection method used to gather information related to qualitative aspects of consumption pattern, solid waste generation and their impact on the water pollution of Pinga Oya. The qualitative data and information collected from in-depth interviews used to build up strong findings and arguments of this study with help of quantitative data generated from questionnaire survey. Fifteen in-depth interviews were used on the basis of purposive sample method. The purposive sampling was useful in selecting the most ideal and relevant stakeholders and key informants representing all the state institutions, civil society organizations and different socio-economic categories. The secondary data and information were collected from the relevant sociological studies, journals, project reports, documents and statistics of Local Government Authorities, Mahaweli Authority, and Divisional Secretariats and Grama Niladharies.

\section{RESULTS AND DISCUSSION}

In the socio-economic and political factors in solid waste generation and its impact on water pollution in the Pinga Oya catchments, many significant findings came up in relation to links among households about income, consumption, lifestyle and solid waste generation. According to the household questionnaire survey conducted in four divisional secretariats of Pinga Oya catchments, $89 \%$ of respondents stated that Pinga Oya is mainly polluted due to solid waste disposal and rest of the respondents disagreed with this statement. Moreover, $53 \%$ of respondents expressed that the monthly household income and amount of solid waste generated are related and $47 \%$ of the respondents indicated that there is no relation between these two variables. In another finding, $40 \%$ of respondents agreed with the statement "solid 
waste generation and life style are related" and 33\% respondents made no response in this regard and rest of the $17 \%$ disagreed with the statement.

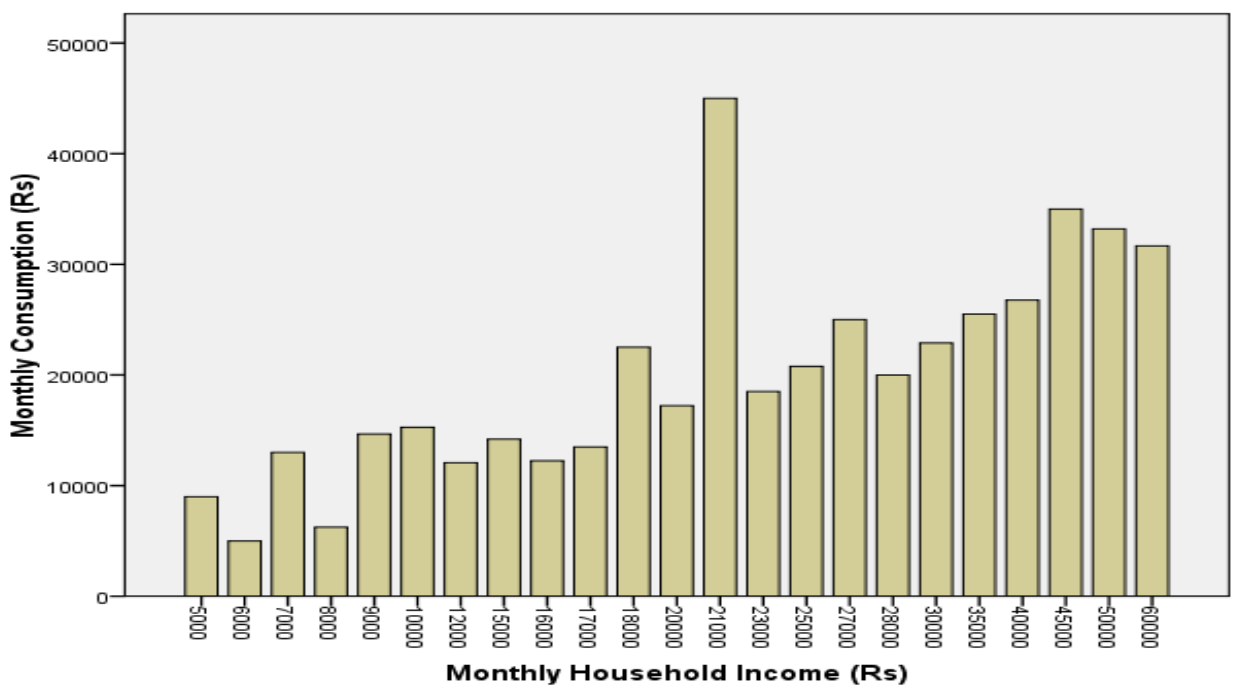

\section{Fig. 2. The relationship between monthly household income and monthly consumption}

According to Fig. 2, when the monthly household income of sample population increased, the amount of money spent for monthly consumption also increased. There was a positive relationship between monthly household income and monthly consumption but there were few places where this positive relationship was disturbed by fluctuating trends. However, in general, the relationship between monthly household income and monthly consumption was positive. The monthly household income and consumption of sample population were higher than other three Divisions. It is also important to mention that only the middle and upper middle class of the respondents spend higher amount for their monthly consumption because of their higher buying capacity caused by higher level of monthly household income. Sometimes, considerable number of respondents was reluctant to indicate their monthly income and amount spent for consumption for the fear of being caught in the government tax. It is necessary to know as to how and why these people possessed higher purchasing power. In other words, it is important to identify what in fact determines the purchasing capacity of these respondents.

Business related employment is the leading mode of income source of many of these people. They engage in various business activities in many parts of Sri Lanka and even at international level. They are mainly involved in business such as rice, spice, timber, garment and vehicles in Kandy, Kurunegala, Kegalle, Polonnaruwa, Anuradapura and Colombo towns. A considerable number of individuals in Akurana (at least one from each middle or upper middle class family) are engaged in various kinds of overseas employments or business in countries such as Japan, South Korea, England, Switzerland, South Africa and Botswana. Thus, Akurana receives a high amount of foreign remittance as well as income from local business centres. In addition to this inflow of income, Akurana is also a leading business town in Kandy District. Therefore, according to the qualitative information and 
data, the higher amount of income is one of the major factors determining the purchasing power of people.

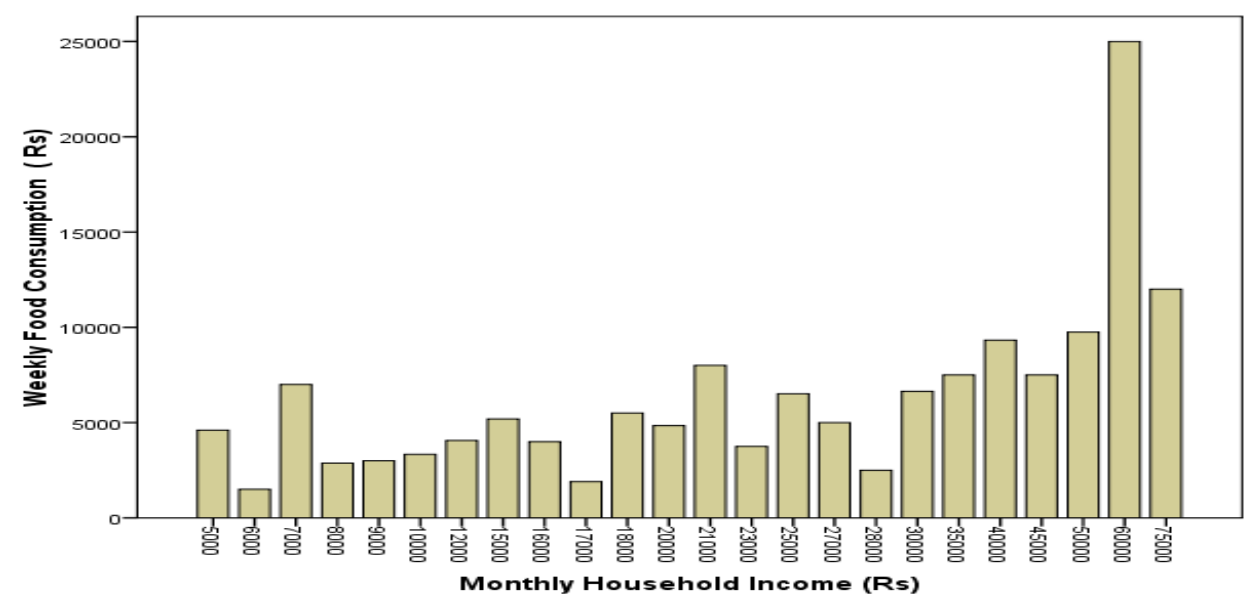

Fig. 3. The relationship between monthly household income and weekly food consumption

Another important factor that determines their consumption is more enjoyment of food. Majority of these respondents are engaged in jobs in foreign countries and outside their areas and work hard to make profit. When they return to their family with sufficient economic potential, they spend unlimited amount of money for consumption in order to please their family materially. Sometimes, those who had foreign exposure of luxury life attempt to achieved the same in their local culture by consuming foods at their day-to-day routine. According to the questionnaire survey, $38 \%$ of respondents stated that they bought food from supermarkets (food cities), 44\% bought from normal shops close to their residence and rest $(18 \%)$ had no specificity in purchasing food stuff. Figure 3 illustrates the relationship between monthly household income and the amount of money spent for the weekly food consumption. It clearly indicates that there is positive relationship between income and the weekly food consumption with some fluctuation.

It is important to note that some specific marriage customs and rituals among Akurana Muslims indirectly influence their consumption patterns. The semi- matrilineal social system and custom of practicing dowry house has been related to their marriages. The bridegroom remains with the bride's house or her mother's house after the marriage. This is almost equal to the matri-local marriage (binna marriage). But this dowry house practice has been changing since recent past. Here, the residential properties of parents directly pass to girls and those immovable properties are given as dowry to men at their marriage transaction. In addition to dowry house customs, the endogamous marriage (custom of marrying within the same caste or particular village) practice was very popular among Akurana Muslims. All these marriage ritual related Akurana Muslims have brought many changes in the demographic and geographic backgrounds of Akurana. Spending a large amount of money for construction of houses, increasing housing density and emergence of new consumption culture are some of those changes. All these socio-economic issues related to environment have been generating more and more solid waste and polluting water of Pinga Oya. It is common to see more than one married daughter living in different separated houses under 
one roof. In these physically non-separated extended residential systems, they separately cook and run their families with less influence from their parents. This kind of specific extended family system is not found in any other Sri Lankan Muslims. As a result of these extended family set up, there is competition for purchasing goods and wasting of food. These make the foundation for over and useless consumption and generate more bio-degradable solid waste. Here, it is important to understand the role of women in determining consumption and purchasing goods. It is the women who mostly determine the consumption under these circumstances.

Table 2. Determining and purchasing food by ethnic group

\begin{tabular}{lllllll}
\hline \multirow{2}{*}{ Person } & \multicolumn{3}{c}{ Determining No } & \multicolumn{3}{c}{ Purchasing No } \\
\cline { 2 - 7 } & Sinhalese & Muslims & \multicolumn{1}{c}{ Total } & Sinhalese & Muslims & Total \\
\hline Husband & $7(12)$ & $17(20)$ & $24(12)$ & $22(38)$ & $88(62)$ & $110(55)$ \\
Wife & $37(63)$ & $64(45)$ & $101(55)$ & $21(36)$ & $16(11)$ & $37(18)$ \\
Both & $9(15)$ & $47(33)$ & $56(28)$ & $08(13)$ & $17(12)$ & $25(13)$ \\
Others & $5(09)$ & $14(15)$ & $19(10)$ & $07(12)$ & $21(15)$ & $28(14)$ \\
Total & $58(100)$ & $142(100)$ & $200(100)$ & $58(100)$ & $142(100)$ & $200(100)$ \\
\hline
\end{tabular}

Numbers in parenthesis indicate percentages.

Table 2 lists the nature of determining and purchasing food on gender basis. This table also describes how Sinhalese and Muslims are involved in determining and purchasing processes. According to Table 2, 55\% of decisions regarding food consumption are made by wives and again even in the corporative decision making process (28\%) wives play a crucial role. There is no difference between Sinhalese and Muslims with regard to female dominance in determining food. With regard to purchasing, mainly husbands are engaged in purchasing process. According to the above data, 55\% of purchasing is carried out by husbands. Here, it is important to note that Muslim males are mainly involved in purchasing than female.

It is necessary to understand that although Muslim women mostly determine what is to be purchased, they have limited access to purchase those goods from the shops. Depending on their class background and religiousness, these women's purchasing freedom of goods from shops is determined. It is mostly the culture that restricts Muslim women's free involvement in purchasing. However, Sinhalese women enjoy more freedom of buying goods from the shops compared to Muslim women. However, in both communities, women enjoy more freedom within their domestic premises in terms of determining what is to be purchased.

Women can control the generation of solid waste by reducing waste rich consumption as domestic managers. For this purpose, women have to make use of economic, technical and behavioral dimensions (knowledge) of minimizing waste generation within their households. According to these three dimensions, women can control consumption pattern through rational economizing of purchasing of food, technological management of available food and changing the behaviour related to over-consumption. The field study further reveals that $88 \%$ respondents agree with the statement that women can control solid waste generation within their household premises and $12 \%$ of respondents disagree with this idea.

The relationship between food consumption and waste generation is another important factor that needs to be understood in terms of solid waste generation and its impact on water pollution of Pinga Oya. This is the most important finding that requires to be emphasized in order to understand the major objective of this paper. The relationship between monthly household income and weekly food consumption is presented in Fig. 4. The weekly 
consumption is presented as the continuous variable based on amount of money spent on food items. The data on daily waste generation were collected from the questionnaire survey conducted. The solid waste samples were collected from selected households over one week in order to verify the questionnaire data.

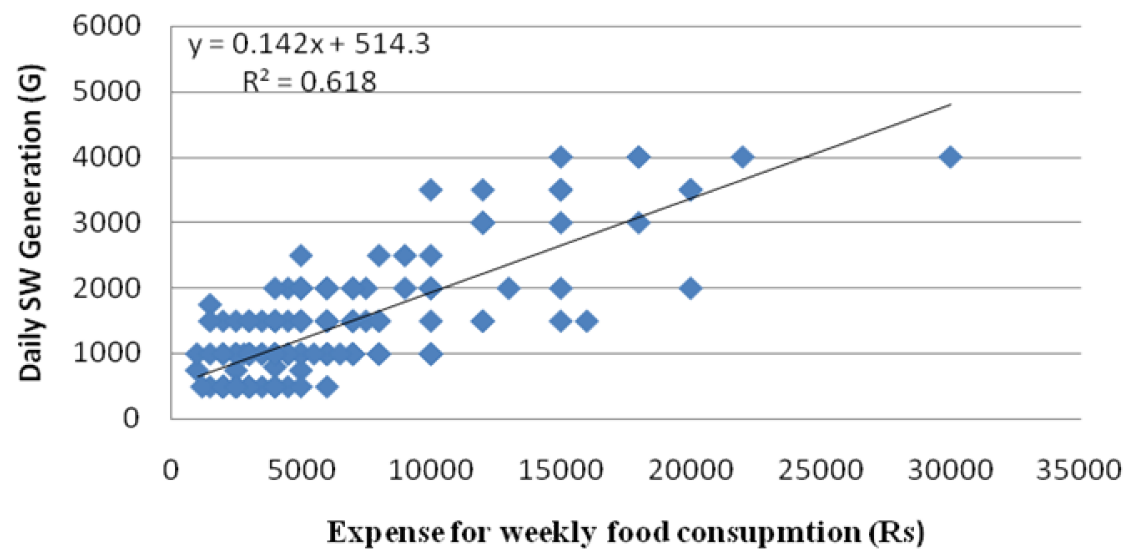

Fig. 4. The relationship between daily household solid waste generation and weekly food consumption

Figure 4 explains the positive relationship between the waste generation and consumption by this regression analysis. This figure brings out the positive causality between weekly food consumption and daily waste generation. This regression analysis clearly indicates that the daily domestic solid waste generation is explained by weekly food consumption $\left(\mathrm{R}^{2}=0.611\right)$.

As explained above, these respondents always try to enjoy with their family members by consuming more and more food. The symbolic consumption is found to be very popular among them. Majority of the middle class and upper middle class people prefer to purchase goods from supermarkets and they are interested in buying packed and bottled foods, vegetables and fruits for this purposes. People who have high purchasing capacity because of their high monthly income consume more goods and generate more solid waste (Fig. 5).

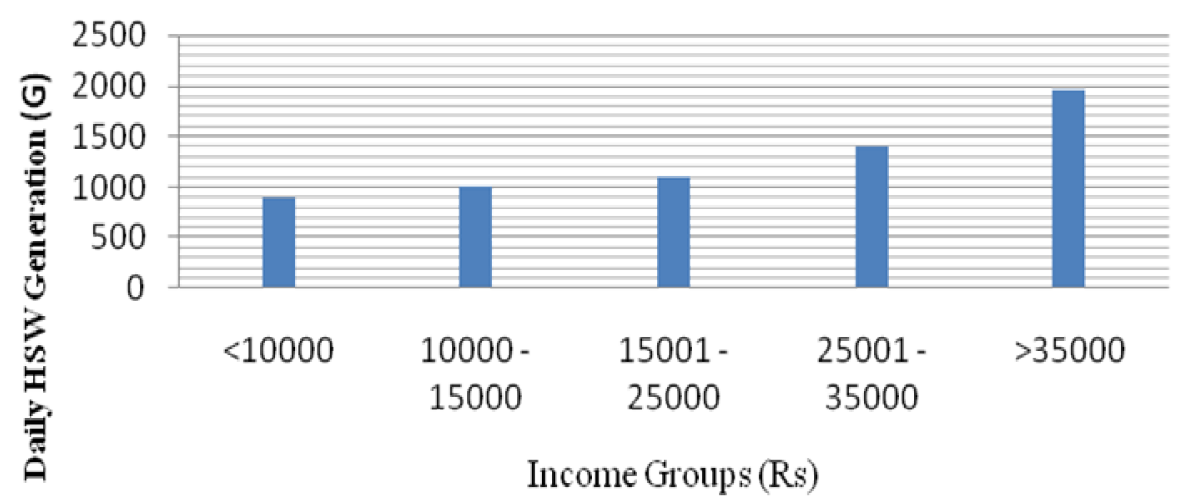

Fig. 5. The relationship between $\mathrm{HH}$ income groups and daily $\mathrm{HH}$ solid waste generation 
Figure 5 illustrates the relationship between the different income groups and daily solid waste generation at household. It clearly indicates that the high income groups generate higher amount of solid waste and the lower the income lower the solid waste generation due to their consumption power. For example, people who earn monthly income less than Rs. 10000 generate solid waste less than $1 \mathrm{~kg}$ whereas people earning over Rs. 35000 monthly income generate approximately $2 \mathrm{~kg}$ of solid waste per day.

According to the report of Ministry of Environment and Natural Resources of Sri Lanka (2005), the daily solid waste generation of Akurana Pradeshiya Shabawa (PS) is $4500 \mathrm{~kg}$ and the composition of waste collection is bio-degradable (short term) $48 \%$, bio-degradable (long term) $18 \%$, polythene and plastic $5 \%$, metal $3 \%$, wooden $7 \%$, glass $5 \%$, paper $3 \%$, building materials $5 \%$, slaughter house 3\%, saw dust/paddy husk/cloth/garment waste 3\%. Even though Akurana is a Pradeshiya Shaba (Village Council), it generates more solid waste daily than that of many urban councils and Pradeshiya Shabas (PS) in Kandy District. For example, Akurana PS (4500 kg/day) generates more solid waste than Nawalapitiya (4000 kg/ day) and Kadugannawa (1476 kg/day) Urban Councils and Harispathtuwa (3000 kg/day), Pathadumbara (1000 kg/day), Pujapitiya (1000 kg/day) PS.

It is clear that Akurana generates mostly bio-degradable household solid waste. The positive relationship between consumption and solid waste generation and the causal impact of monthly consumption on daily solid waste generation can be well understood by the priority preference of goods purchased. According to the field data, respondents' priority preference was vegetable and fruits $96 \%$, dry food items $94 \%$, fish and flesh $77 \%$, sanitary items $62 \%$, packed or bottled food or drink 58\%, pharmaceutical items $58 \%$ and others $30 \%$. The interesting factor is that most of leftovers of these purchased items can be largely found in the solid waste collection. Since people consume many of these goods in large scale at their daily routine more and more bio-degradable solid waste accumulates in Akurana area. It was also revealed that people in Akurana very often are in the habit of having parties and functions with their relatives and friends. Moreover, regardless of class difference, they spend a large sum of money for marriage festivals and rituals. This is a salient feature of Akurana community motivated by their peculiar culture and economic potentials. As a result, demand for food is always high and symbolic consumption is developed within the community. The entire society is based on consumption culture and losing collective consciousness in terms of environmental conservation. It is further proved by Table 3 which presents multiple regression results of factors affecting household solid waste generation

Table 3. Factors affecting household solid waste generation

\begin{tabular}{|c|c|c|c|c|}
\hline \multicolumn{2}{|l|}{ Variable } & Coefficient & Standard error & $p$-value \\
\hline \multicolumn{2}{|l|}{ Weekly consumption of food (Rs) } & 0.362 & 0.014 & 0.005 \\
\hline \multicolumn{2}{|l|}{ Floor space of house $(\mathrm{sq} / \mathrm{ft})$} & 0.039 & 0.094 & 0.746 \\
\hline \multicolumn{2}{|l|}{ Family size } & 0.560 & 42.111 & 0.000 \\
\hline \multicolumn{2}{|l|}{ Gender } & 0.064 & 124.026 & 0.527 \\
\hline \multicolumn{2}{|l|}{ Ethnicity } & 0.170 & 156.392 & 0.169 \\
\hline Adjusted R Square & 0.472 & & & \\
\hline Number of cases & 200 & & & \\
\hline
\end{tabular}

Significance at a level of 0.05

According to the Table 3, only weekly food consumption and family size are found significant (at the level of 0.05 ) in influencing the daily domestic solid waste generation. In 
this study, $62 \%$ of respondents agree with the statement that solid waste generation can be controlled by reducing consumption, $32 \%$ of respondents disagree with this statement and rest $6 \%$ did not respond in this regard.

\section{CONCLUSION}

Mahaweli River is utilized for agricultural, domestic and electricity generation. Water pollution in Mahaweli has brought up many serious socio-economic and environmental issues. Sometimes it will turn as water related political conflicts among different sectors and people. The current challenge of water pollution in Mahaweli will be further aggravated and create various new health, administrative and environmental problems. The solid waste disposal, discharging of waste water and soil erosion are major causes of water pollution in Mahaweli. In the recent past, the degree of water pollution has gone up in the city and suburb areas through which Mahaweli and its tributaries flow due to rapid urbanization. Pinga Oya, one of the main tributaries of River Mahaweli, is polluted mainly by improper solid waste disposal which has adverse impact on Upper Mahaweli catchment.

The direct solid waste disposal into Pinga Oya water and having dumping sites near or on the river and canal banks have been one of the leading causes of water pollution. There are many dwellers issues and inter-institutional conflicts in relation to solid waste management. Also, people are not very much concerned about the negative impact of solid waste disposal into water. It is the domestic solid wastes that are largely found in waste collection and most of these domestic solid wastes are produced by day-to-day consumption of households.

The sociological study carried out to determine the relationship between the consumption pattern and solid waste generation in the Pinga Oya catchment and reviewing of available sociological literature help understand the causal link between solid waste generation and consumption pattern. Thus, it is extremely difficult to understand the seriousness of solid waste problem without analyzing the consumption culture of people. The gender relation is another variable determining consumption culture. The locality as well as the urban neighborhood which can differently manipulate consumption culture is very important in this regard. Consumption is integrated into the everyday life of individuals and it is typical of various time periods and various societies. Moreover, individuals construct their sense of self and their sense of society through consumption.

Although the modern consumption patterns facilitate day-to-day human life in various respects by reducing their workloads and saving their time, the modern consumption has become good servant as well as bad master in terms of sustainable development. Thus, it is clear that people of this modern society are very much influenced by the material culture of latest capitalism with the help of mass media. As a result, people do not consume their actual needs but made to be consuming symbolic values of the goods. This kind of artificial consumer society always promotes unwanted and environmentally harmful production and consumption. The artificially created consumption pattern or consumer society has to be responsible for generating more and more solid waste as one of the serious environmental problems.

In order to minimize the negative impact of consumption pattern on the increasing solid waste generation, there should be a morality in consumption. The idea of morality can have a considerable impact on consumption pattern to achieve an environmentally friendly consumer society. The environmentally friendly socialization, education, attitude and 
awareness can form moral consumer behaviour. Thus, development and environmentally friendly personalities or consumer culture will minimize solid waste generation and help to implement successful solid waste management and conservation of water resources.

\section{ACKNOWLEDGMENTS}

Authors wish to express their gratitude to Professor, K. Tudor Silva, Department of Sociology, University of Peradaeniya, all academic staff members of Department of Agricultural Engineering, University of Peradeniya, and Dr. A. P. Keerthipala, the former research coordinator of Crossing Boundaries. Finally, our thanks go to the Crossing Boundaries Project for its financial support.

\section{REFERENCES}

Baudrillard, J. (1988). Consumer Society pp. 29-56. In Jean Baudrillard (Ed.) Selected Writings Mark Poster, Stanford University Press, Stanford, NY.

Census \& Statistic Department (2007). Kandy Census Handbook, Regional Office, Kandy, Sri Lanka.

Cuff, E.C, Sharlock, W.W. and Francis, W.D. (2004). Perspectives in Sociology. London, UK.

Herath, G (2003). Pollutions inflows to Mahaweli from Kandy city suburbs; A case study from Sri Lanka, The first International Symposiam on Southeeast Asian Water Environment October 23- 25.

Hettiarachchi, M. (2003). Problems in Pinga Oya Basin, Net Water/CDI Partnership. Available on: www.cap-net.org.

Ministry of Environment and Natural Resources (2005). Municipal Solid Waste in Sri Lanka.

Ministry of Forestry and Environment (2000). State of the Environmental Report Sri Lanka, Development, Environment and Management Associates/ NORAD UNEP, SACEP.

Slater, D.R (1997). Consumer Culture and Modernity, Polity Press, Cambridge, UK.

Uusitalo, O. (1996). Consumption and Environment, Business and Organization Ethics Network, pp. 14.

Werellagama, D.R.I.B. (2000). Collaborative program to prevent pollution of the Upper Reaches of Mahaweli River, Department of Civil Engineering, Faculty of Engineering, University of Peradeniya, Sri Lanka. 